\title{
椎骨動脈起始部閉塞性病変に対する椎骨動脈一総頸動脈 transposition
}

\author{
宇野 昌明，鈴江 淳彦，永廣 信治
}

\section{Surgical Treatment for Patients with Bilateral Occlusive Vertebral Artery Lesions}

Masaaki Uno, M.D., Atsuhiko Suzue, M.D., and Shinji NaGahiro, M.D.

Department of Neurosurgery, School of Medicine, The University of Tokushima, Tokushima, Japan

Summary: We evaluated the surgical and long-term follow-up results of VA-CCA transposition in patients with bilateral VA occlusive lesions. Indications for this operation are: 1) symptomatic patients with the infarction in the cerebellum, brain stem or occipital lobe, 2) symptomatic patients with more than 50\% VA stenosis with contralateral VA occlusion, 3) symptomatic patients with more than $75 \%$ bilateral VA stenosis at origin. In 13 patients, there were no deaths and no major complications. During the follow-up period, 1 patient died of a cardiac event, and another patient had a reattack due to the restenosis of VA stenosis. Another 11 patients showed no reattacks and good patency of VA.

Although there have been no prospective randomized studies for this disease, VA-CCA transposition is a safe and useful treatment for patients with bilateral VA origin occlusive lesions.

\author{
Key words: \\ - vertebral artery \\ - stenosis \\ - transposition
}

Surg Cereb Stroke

(Jpn) 32: 403-407, 2004

\section{はじめに}

脳梗塞のうち posterior circulation が原因となる率は全 体の約 $25 \%$ であり, このうち動脈硬化性病変が最も起こ りやすい部位は椎骨動脈起始部である ${ }^{2)}$. しかし, めまい などの非特異的な症状が多いことやMRA, 頸部エコーな どでは起始部病変が診断しにくいことより, 椎骨動脈起始 部病変を診断することは容易ではない1)10)13). また脳血 管撮影でも起始部狭窄病変を見逃すこともある ${ }^{8)}$.ゆえに, 頸動脈病変に比較してその頻度や予後についての詳細な報 告は少ない. また，この椎骨動脈起始部病変が原因である
場合の治療法の選択も確立されていないのが現状である. 今回われわれは, 椎骨動脈起始部病変に対して, 厳密な手 術適応のもとに施行した血行再建術の手術方法およびその 成績について報告する。

\section{対象と方法}

\section{1. 手術適応}

以下の症例に対して血行再建術の適応ありとした。(1)小 脳・脳幹・後頭葉に病変を有し, その虚血症状を呈する症 例で，かつ(2)反対側椎骨動脈の閉塞があり，手術側は50\% 以上の椎骨動脈起始部狭窄を有する症例，あるいは(3)両側

徳島大学 脳神経外科(受稿日 2004.6.16)〔連絡先： =770-8503 徳島市蔵本町 3丁目 18-15 徳島大学医学部 脳神経外科 宇野昌明〕 [Mailing address: Masaaki Uno, M.D., Department of Neurosurgery, School of Medicine, The University of Tokushima, 3-18-15 Kuramoto-cho, Tokushima City, Tokushima 770-8503, Japan] 


\begin{tabular}{ccccccc} 
Table 1 & Case summary & \multicolumn{5}{l}{} \\
\hline Case & Age & Sex & Side & Symptoms & Lesion & Risk factors \\
\hline I.K. & 46 & $M$ & $L$ & Vertigo & R-medulla & DM,HL \\
M.R & 48 & $M$ & $L$ & Vertigo, headache & R-cerebellum & $H T, H L$ \\
J.S & 61 & $M$ & $L$ & Vertigo, headache & R-cerebellum & Tb \\
F.T & 63 & $M$ & $R$ & Vertigo & - & $H T$ \\
I.M & 70 & $M$ & $L$ & Vertigo & L-cerebellum, & \\
& & & & & R-occipital & - \\
K.S & 51 & $M$ & $L$ & Vertigo, headache & L-cerebellum & $H T, H L$ \\
H.I & 71 & $M$ & $L$ & L-hemianopsia & L-occipital & $H T$ \\
S.T & 63 & $F$ & $R$ & Vertigo & R-pons & $H T$ \\
S.M & 66 & $M$ & $L$ & Vertigo & Bilat.cerebellum & - \\
Y.K & 61 & $M$ & $L$ & Disorientaion & R-thalamus & - \\
T.T & 71 & $M$ & $R$ & Vertigo & L-cerebellum & DM,HT \\
Y.S & 58 & $M$ & $L$ & R-hemiparesis & L-pons & DM \\
Y.Y & 63 & $M$ & $R$ & Vertigo & L-cerebellum & DM,HT \\
\hline
\end{tabular}

$\mathrm{HL}$ : hyperlipidemia, $\mathrm{HT}$ : hypertension

椎骨動脈起始部が $75 \%$ 以上の狭窄を呈する症例を手術適 応があると判断した，椎骨動脈の狭窄はすべて脳血管撮影 で確認した。また虚血部はdiffusion MRIあるいはT2MRIで診断した.

\section{2. 対 象}

1997 年 12 月から 2003 年 12 月までに当科で椎骨動脈起 始部病変に対して血行再建術を施行した 13 例を対象とし た (Table 1)。男性 12 例, 女性 1 例で, 平均年齢は 61 歳 (46-71歳)であった。手術側は左が 9 側, 右が 4 側であっ た。虚血症状はめまいで発症した症例が 10 例と最も多く, ついで片麻疩 1 例, 見当識障害が 1 例, 同名半盲 1 例であ った. risk factor としては高血圧が 7 例と最も多かった。

\section{3. 手術方法}

手術は全身麻酔下に supine positionをとり，胸鎖乳突 筋前縁から鎖骨上縁にかけL型に $8 \times 6 \mathrm{~cm}$ の皮切を置いた (Fig. 1A)。ついで胸鎖乳突筋の胸骨柄を切断し, 内頸静 脈, 総頸動脈を $\mathrm{R}$ 離する。 その間をより深く $\mathrm{R}$ 離し, 迷走 神経を free として, 総頸動脈側に $\mathrm{R}$ 離しておく。この部 の深層の脂肪組織を $\mathrm{R}$ 離していくと交感神経幹が認められ る (Fig. 1B)。この本幹を温存しながらR 離すると C6 椎体 の横突起が触れるようになり, その中枢側で椎骨動脈の拍 動を感知する.椎骨動脈の上部には必ず椎骨静脈が存在し, これを側方へ圧排するか切断すると，椎骨動脈がC6 横突 孔に入る部分が観察される。ここから中枢側に椎骨動脈を $\mathrm{R}$ 離し，鎖骨下動脈分岐部までR 離する(Fig. 1C)。この 際，左では内頸静脈に入る胸管の損傷に，右側では反回神 経の損傷に注意する。ここでヘパリンを 100 単位 $/ \mathrm{kg}$ 静注
し，椎骨動脈を C6 横突孔部でSugita clip で遮断する. 椎 骨動脈起始部にWeck clip をかけ，切断する。交感神経幹 の神経網を潜らせて椎骨動脈起始部を上方に引き上げ，断 端を fish mouthに形成し，総頸動脈を両側で遮断する。 総頸動脈を側壁を上方に起こすようにして，血管パンチ (径 $4 \mathrm{~mm}$ or $5 \mathrm{~mm}$ ) で穴を開ける. 椎骨動脈と総頸動脈の 吻合は 7-0 プロリンで行う。背面は連続縫合し，上面は 1 針ずつ確実に縫合する (Fig. 1D)。椎骨動脈，総頸動脈を 順に開放し，血液を flush out し，もし縫合部より漏れる ようであれば，追加縫合を行う。われわれは術中にDSA で椎骨動脈の patency を確かめたのち，手術を終了する.

\section{結 果}

\section{1. 手術成績}

手術による死亡および major complication は認められな かった，全例で軽度の不全Horner 徴候がみられたが，自 觉症状は認められなかった。

2 例で乳び胸を認めたが保存的加療で治瘉した。術後 MRA または血管撮影で椎骨動脈の patencyを確認した。 退院時の ADLは mRS 0あるいは1が11例，mRS 2 が1 例, $\mathrm{mRS} 3$ が1例であった。この $\mathrm{mRS} 3$ の症例は左大脳 半球梗塞のため, 術前から左片麻疩を認めていた症例で, 今回の手術による症状の増悪はなかった。

\section{2. 追跡成績}

平均 24.9 力月の追跡期間中, 1 例で 4 年後に置換部の再 狭窄を認め，延髄梗塞をきたした。この症例は保存的加療 にもかかわらず TIAを繰り返すため, 左 STA-SCA bypassを施行した。現在は mRS 1 で自立生活を送ってい 

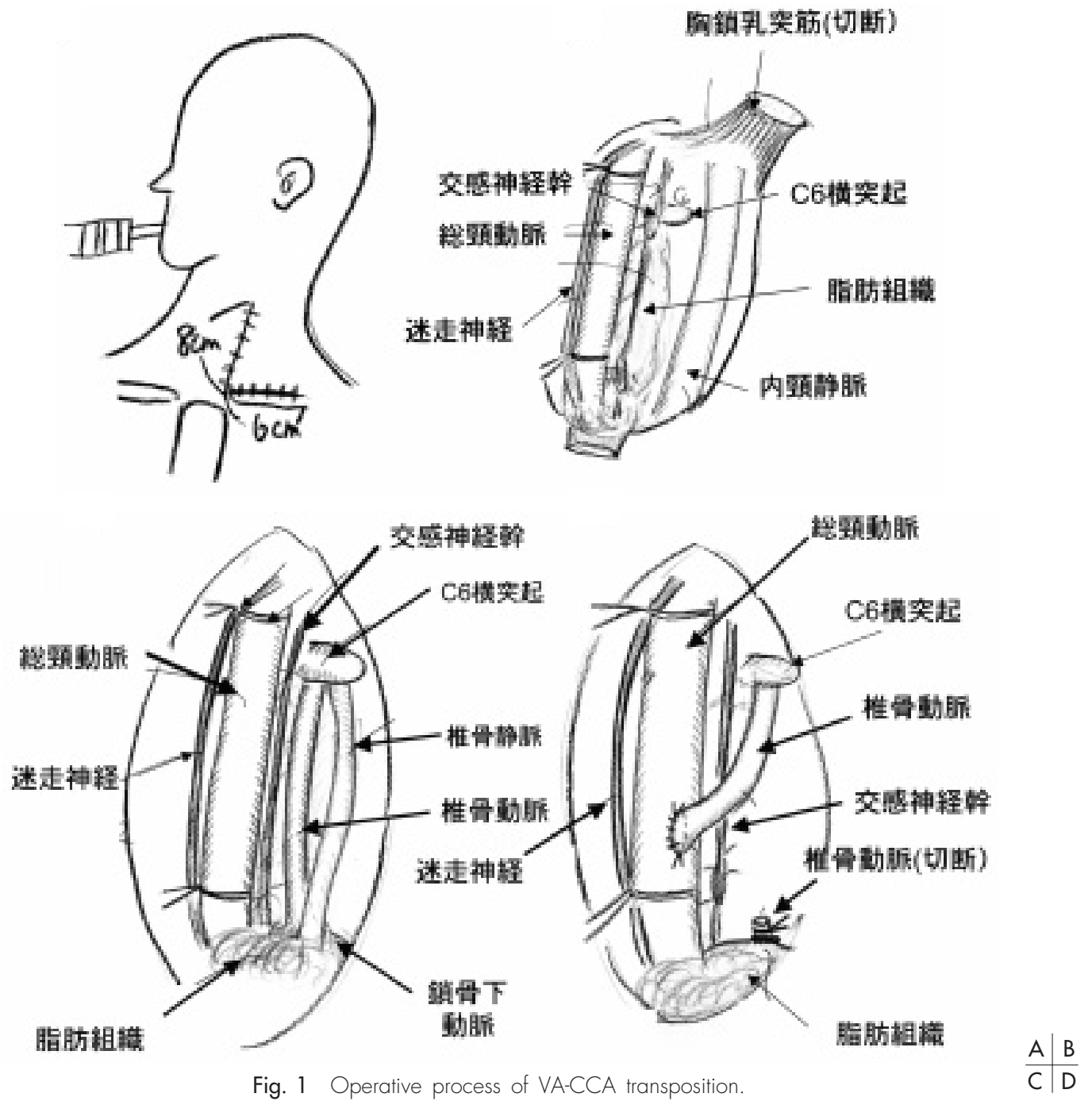

る. 他の 1 例で手術後 6 力月目に心筋虚血が原因で突然死 した。そのほかの症例では再発作を認めておらず，また置 換部の再狭窄も認めていない.

\section{3. 代表症例}

代表的な症例を提示する.

症 例：63歳, 男性.

主 訴：回転性めまい, 嘔吐.

既往歴：糖尿病, 脳梗塞, 心房細動.

現病歴：2003年 6 月 30 日朝より急に回転性めまいと嘔 吐をきたした。明らかな麻瘏はなかったが，救急で近医脳 外科を受診し，脳梗塞を疑われ入院となった。

術前の頭部 MRIで左小脳と右小脳内側下面に脳梗塞を 認めた (Fig. 2A, B). 脳血管撮影では右椎骨動脈起始部に $75 \%$ 狭窄を認め, 左椎骨動脈は閉塞していた (Fig. 3A, B). 椎骨脳底動脈は右椎骨動脈からのみ還流されていた (Fig.
3C).このため右椎骨動脈一総頸動脈 transposition を施行 した (Fig. 4)。術後抗血小板剤および抗凝固剤 (心房細動 があるため)の投与を行っているが手術後再発作を認めず， 術後のMRAでも再狭窄を認めていない.

\section{考 察}

椎骨脳底動脈循環不全や脳幹・小脳・後頭葉の梗塞の原 因として $20 \%$ が椎骨動脈起始部（V1 segment）が原因とな $ろ^{14)}$ 。しかし，その診断は MRA や超音波エコーでは診断 しにくく，脳血管撮影が現在でも gold standard となって いる.この脳血管撮影でも時として狭窄病変の診断は難し い. その理由として椎骨動脈が鎖骨下動脈の上方以外から 出る場合や著明な kinkがある場合，鎖骨下動脈に重なっ て狭窄を見逃すことがある。またカテーテルの先端が狭窄 部に重なって，狭窄部を見逃す場合も報告されている ${ }^{8)}$. ゆえにこの部の診断はたとえ脳血管撮影を施行したとして 


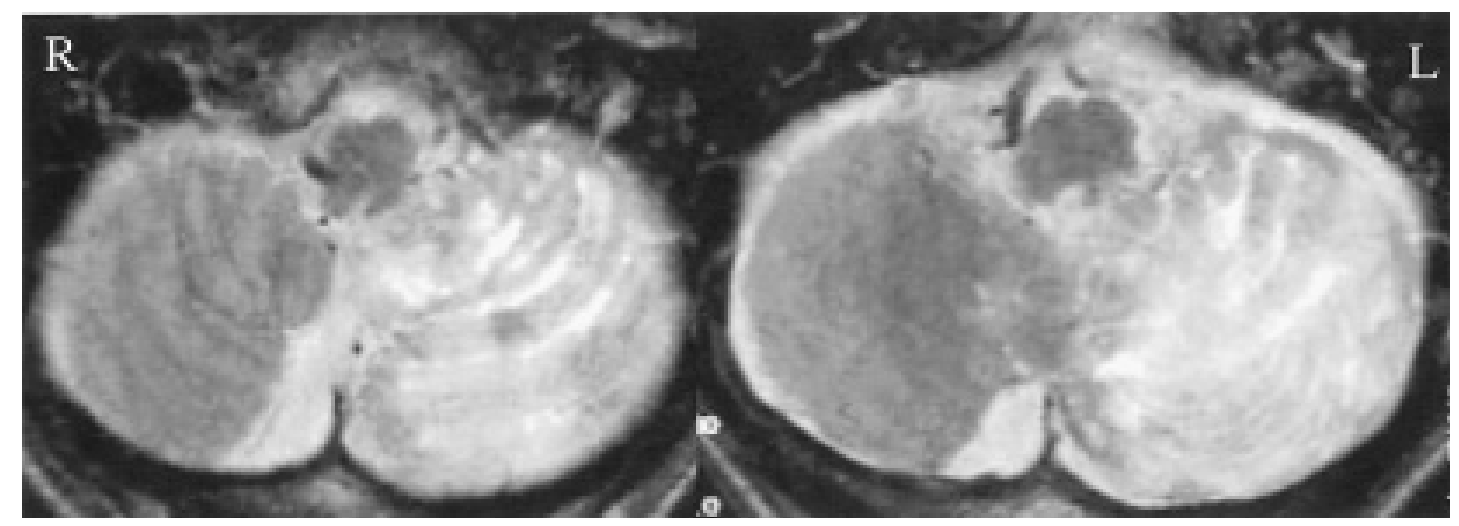

Fig. 2 Preoperative T2-MRI showing infarction in the bilateral cerebellum.
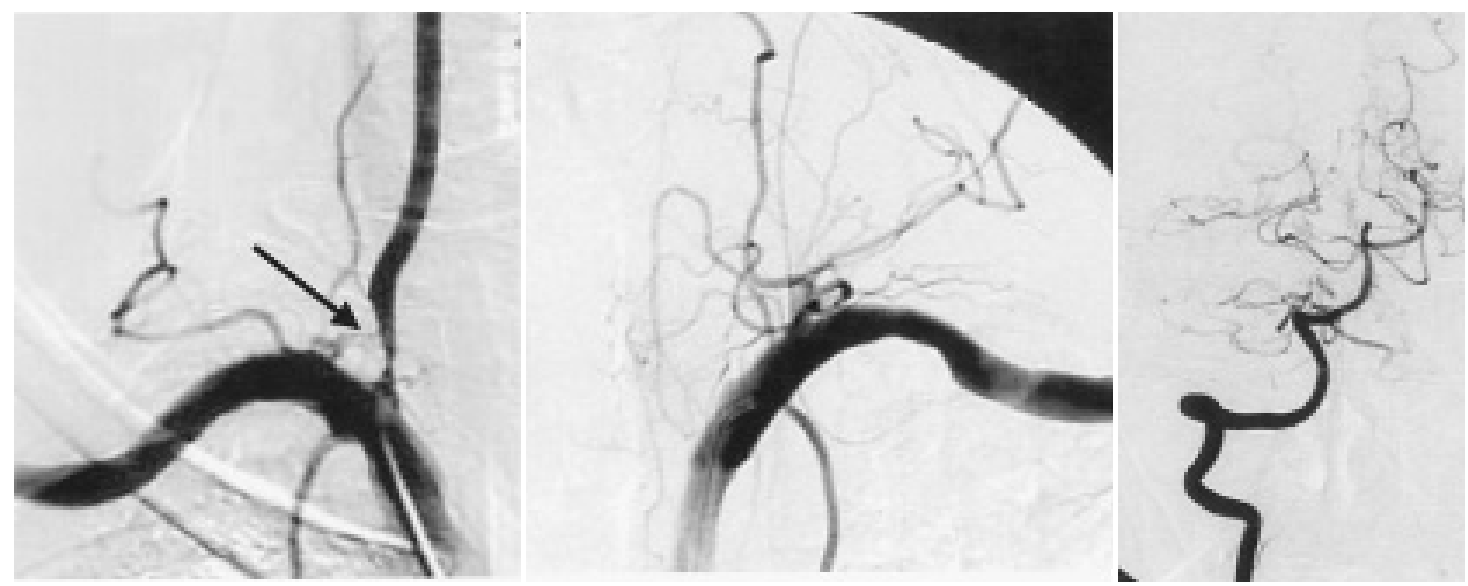

Fig. 3 A: Preoperative right $V A$ angiography showing $75 \%$ stenosis at the origin. B: Preoperative left VA angiography showing the occlusion of VA

$C$ : Preoperative right VA angiography showing no stenosis of VA and BA.

$A|B| C$

も，正確な診断ができにくい．治療を選択するうえで今後 は3D-CTA や 3D-DSA なと，立体的な観察が必要であろ う.

1957 年に Hutchinson らが頭蓋外椎骨動脈の病変が小 脳・脳幹の虚血病変の原因となることを報告して以来，こ の病変に対していろいろな血行再建術が施行されてきた ${ }^{1)}$ 3-7) 9-12). 1960 年以降は椎骨動脈起始部の endarterectomy が血行再建術の標準術式となったが，この手術は技術的に 困難であり，また手術侵襲も大きかったため，Comerら， Edward らが発表した椎骨動脈を総頸動脈に transposition する方法がその後主流となった。この手術の利点は手術侵 襲が小さく，かつ合併症が少ないことがあげられる。 Ogawa ら ${ }^{11}$ はこれに対してVAの鎖骨下動脈への transposition を第 1 選択とし，良好な成績を報告している。近 年ではこの病変に対してPTA, stentによる angioplastyが 報告され，良好な手術成績が報告されている ${ }^{1) 3)}$ 。しかし，
Albuquerque $ら^{1)}$ は自験例 33 例の PTA, Stent の長期追跡 の成績を報告し，初期成績は良好なものの，長期的には moderate to severe stenosis $43.3 \%$ に認め mild stenosisを含めると $66.7 \%$ の症例で再狭窄が認められた。す心゙ ての再狭窄はinstent restenosisであった。この理由とし て, 椎骨動脈起始部は冠動脈起始部や腎動脈起始部と同様 に elastin と smooth muscleが含まれていて recoil が出現 しやすいこと，またこの部の狭窄は smooth で硬く，ステ ントで広げにくく，これも recoilingの理由になること， 椎骨動脈起始部の直径が狭いこと, また起始部は蛇行して おり，ステントで不自然に直線化させることがより再狭窄 を起こす可能性があることなどをあげている．われわれは このような報告を踏まえ，現在は前述したように症候性の 両側病変に限って椎骨動脈一総頸動脈 transposition を第 1 選択として施行し，片側病変に対しては抗血小板剤の投与 で対処している. 


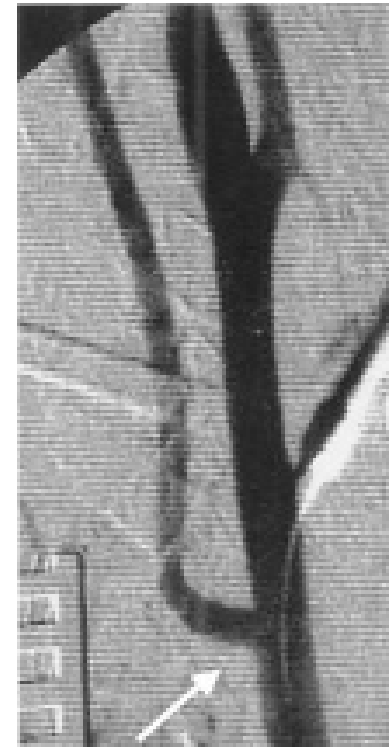

Fig. 4 Intraoperative angiography demonstrating the good patency of right VA (arrows).

椎骨動脈一総頸動脈 transpositionの合併症として以前よ り知られているようにHorner 症候や乳び胸があげられる が，解剖を熟知し，交感神経幹や胸管の位置を十分認識し て損傷させないことが重要である ${ }^{9)}$. 特に胸管は丁寧に結 紮したのち，切断すべきである.

この病変に対する血行再建術の効果を prospective randomized study で検討した報告はなく，また，この病変の 長期予後を検討した報告も少ない. 今後は本邦でも少なく とも, この病変の自然歴, 治療法の case control studyに よる治療成績の検討が必要であろう。

\section{文献}

1) Albuquerque FC, Fiorella D, Han P, et al: Reappraisal of angiopalsty and stenting for the treatment of vertebral origin stenosis. Neurosurgery 53: 607-616, 2003

2) Bamford J, Sandercook P, Dennis M, et al: Classification and natural history of clinically identifiable subtypes of cerebral infarction. Lancet 337: 1521-1526, 1991

3) Cloud GC, Crawley F, Clifton A, et al: Vertebral artery origin angioplasty and primary stenting: saftety and restenosis rates in a prospective series. $J$ Neurol Neurosurg Psychiatry 74: 586-590, 2003

4) Deriu GP, Ballotta E, Franceschi L, et al: Surgical management of extracranial vertebral artery occlusive disease. J Cardiovasc Surg 32: 413-419, 1991

5) Deruty R, Soustiel JF, Pelissou-Guyotat I, et al: Extracranial surgery for vertebro-basilar ischaemia. Experience of 8 cases. Neurological Research 13: 89-93, 1991

6) Diaz FG, Ausman JI, Reyes RA, et al: Surgical reconstraction of the proximal vertebral artery. J Neurosurg 61: 874-881, 1984

7) Edwards WH, Mulherin JL: The surgical reconstraction of the proximal subclavian and vertebral artery. $J$ Vasc Surg 2: 634-642, 1985

8) Farres MT, Magometschnigg H, Grabenwoger F, et al: Stenoses of the first segment of the vertebral artery: difficulties in angiographic diagnosis. Neuroradiology 38: 6-10, 1996

9）藤本俊一郎：機械的圧迫および kinking による頭蓋外椎骨動 脈狭窄に対する血行再建. 脳神経外科 17: 907-916, 1989

10) Imparato AM: Vertebral arterial reconstraction: A nineteen-year experience. $J$ Vasc Surg 2: 626-634, 1985

11) Ogawa A, Yoshimoto T, Sakurai Y: Treatment of proximal vertebral artery stenosis. Acta Neurochir (Wien) 112: 13-18, 1991

12) Spetzler RF, Hadley MN, Martin N, et al: Vertebrobasilar insufficiency. Part 1: Microsurgical treatment of extracranial vertbrobasilar disease. $J$ Neurosurg 66: 648-661, 1987

13) Toi H, Uno M, Harada M, et al: Diagnosis of acute brainstem infarction using diffusion-weighed MRI. Neuroradiology 45: 352-356, 2003

14) Wityk RJ, Chang HM, Rosengart A, et al: Proximal extracranial vertebral artery disease in the New England Medical Center Posterior Circulation Registry. Arch Neurol 55: 470-481, 1998 